\title{
Operação Ninja: Um Jogo Educacional Digital para Auxiliar na Aprendizagem das Quatro Operações Básicas da Matemática
}

\author{
Arthur da S. Araújo ${ }^{1}$, Vinicius dos S. de Oliveira ${ }^{1}$, Vinicius de S. Oliveira ${ }^{1}$, Valter \\ dos S. Mendonça Neto ${ }^{1}$, Carlos C. Cardoso ${ }^{1}$ \\ ${ }^{1}$ Instituto Federal de Educação, Ciência e Tecnologia do Maranhão - IFMA - Campus \\ Açailândia - Maranhão, MA - Brasil \\ \{araujo.arthur, o.vinicius, souzav\}@acad.ifma.edu.br, \{valter.neto, \\ carlos.costa\} @ifma.edu.br
}

\begin{abstract}
This article aims to present a digital educational game, called Operação Ninja, developed to assist students of the fourth grade, from Elementary School, in the process of learning the Mathematics' basic operations. For the building up of the game, the tool Scratch was used, a programming language utilized to create animated stories, games and other interactive programs. The game's purpose is to make the learning of calculations more pleasant and closer to the children's reality, becoming a valuable instrument for a significant improvement in the teaching of Mathematics.
\end{abstract}

Resumo. Este artigo tem como objetivo apresentar um jogo educacional digital denominado, Operação Ninja, desenvolvido para auxiliar alunos do $4^{\circ}$ ano, do Ensino Fundamental, no processo de aprendizagem das operações básicas da Matemática. Para a construção do game, utilizou-se a ferramenta Scratch, uma linguagem de programação usada para criar histórias animadas, jogos e outros programas interativos. O jogo consiste em uma proposta para tornar o aprendizado dos cálculos mais prazeroso e próximo da realidade das crianças, tornando-se um instrumento valioso para uma melhoria significativa no ensino da Matemática.

\section{Introdução}

O ensino e aprendizagem de Matemática são de extrema importância para o desenvolvimento social e a formação profissional do sujeito, pois a capacidade de estabelecer o raciocínio lógico matemático em tarefas do cotidiano, como passar um troco, realizar uma compra com desconto, efetuar medições, são triviais para que uma pessoa torne-se independente [Batista, Ramos e Brito 2018].

Mesmo diante da relevância que a Matemática exerce, nota-se que em diferentes escolas brasileiras, nos variados níveis escolares, é comum se identificar alunos com grandes dificuldades em relação à disciplina. Segundo Coelho Neto, Blanco e Silva (2017), na maioria das vezes, essas dificuldades estão ligadas aos conceitos básicos da área, principalmente, relacionadas às operações matemáticas fundamentais e suas estruturas. 
No monitoramento do Programa Todos pela Educação (2019), apesar do crescimento comparado ao último ano, apenas 48,9\% dos alunos estão acima do nível considerado adequado. No Brasil, os dados do Índice de Desenvolvimento da Educação Básica (IDEB) e do Programme for International Student Assessment (PISA) indicam que o desempenho dos alunos em Matemática é bastante deficiente. Em muitos casos, as consequências perduram nas etapas escolares seguintes, apresentando-se com um grande entrave no ensino superior [Brandão et al. 2017].

Estudos apontam esforços para a criação de metodologias, técnicas e softwares para a melhoraria do ensino e aprendizagem da Matemática. Nesta linha, os jogos educativos digitais, principalmente, devido aos aspectos lúdicos, possibilitam ao aluno potencializar a aprendizagem de conceitos, conteúdos e habilidades presentes nos jogos [Macêdo, Moutinho e Santos 2017].

Neste contexto, este trabalho apresenta o desenvolvimento de um protótipo de jogo educativo para o ensino da Matemática denominado Operação Ninja, que aborda especificamente, o conteúdo das quatro operações, para alunos da $4^{\mathrm{a}}$ série do Ensino Fundamental.

\section{Fundamentação Teórica}

Alfabetização Matemática é um fenômeno que trata da compreensão, da interpretação e da comunicação dos conteúdos matemáticos ensinados na escola, considerados como iniciais para a construção do conhecimento matemático [Danyluk 1988].

$\mathrm{Na}$ literatura, pesquisas apontam que esse processo de alfabetização não é trivial. A dificuldade em aprender Matemática é percebida, constantemente, nos depoimentos dos estudantes do ensino fundamental. Resende e Mesquita (2013) relatam que é comum os alunos declararem que não gostam da disciplina, de que a temem e a consideram uma disciplina complexa. O problema acompanha os discentes nos anos posteriores, principalmente, sobre o conceito e regras das quatros operações [Souza et al. 2018].

Segundo Notare e Behar (2010), muitos docentes, durante o ensino da Matemática, percebem as dificuldades dos aprendizes e, diante disso, buscam novas estratégias pedagógicas para o ato de ensinar. Entretanto, ainda existe muita resistência, por parte de alguns docentes, em mudar as metodologias tradicionais de ensino.

$\mathrm{Na}$ busca por caminhos mais favoráveis à aprendizagem Matemática, os jogos educacionais digitais trazem grandes contribuições para o ensino e fixação de conteúdos para crianças do Ensino Fundamental. Para Gonçalves et al. (2014), estes jogos na disciplina tornam o aprendizado mais prazeroso e mais próximo da realidade das crianças e, quando canalizados para os estudos, podem ser instrumentos valiosos para a melhoria significativa nos estudos.

De acordo com Teixeira (2015), em muitos casos, a mesma operação que o aluno não consegue resolver em sala de aula, é resolvida sem maiores dificuldades quando abordada dentro de um jogo educacional digital. Assim, a interação com esses jogos para este contexto, dinamizam o processo de aprendizagem como alternativa a resolução de problemas presentes em livros didáticos.

Apesar de existirem diversos softwares educativos para o ensino de Matemática, em sua maioria, aqueles caracterizados como "exercício" e "prática" são mais comuns. 
Para Silva e Gomes (2015), este tipo de software é semelhante às atividades presentes em antigos livros didáticos e, idealmente criados para serem aplicados quando o aluno já possui um conhecimento prévio sobre o assunto abordado. Nestes casos, aspectos característicos associados ao lúdico são pouco explorados, principalmente, no sentido de promover prazer ao ato de jogar e sua influência no processo de aprendizagem.

\section{Desenvolvimento do game}

O jogo Operação Ninja foi idealizado e produzido por um grupo de alunos do Curso Técnico em Informática, de uma instituição pública de ensino, como atividade avaliativa da disciplina de Introdução a Lógica de Programação. Foram realizados 20 encontros presenciais, dividido em 5 etapas baseadas em Novak (2011), conforme Tabela 1 a seguir:

Tabela 1. Etapas de desenvolvimento

\begin{tabular}{|c|c|}
\hline Etapas & Descrição \\
\hline Apresentação & $\begin{array}{l}\text { Explicação do conceito de jogos educativos, suas características e o processo de } \\
\text { criação. }\end{array}$ \\
\hline Treinamento & $\begin{array}{l}\text { Apresentação da ferramenta de desenvolvimento, assim como seus principais } \\
\text { elementos e comandos }\end{array}$ \\
\hline Idealização & $\begin{array}{l}\text { Definição dos elementos e características como: assunto abordado (quatro } \\
\text { operações matemáticas), público-alvo (crianças do } 4^{\circ} \text { ano do Ensino } \\
\text { Fundamental), inspirações (jogos de plataforma), objetivo-enredo (o } \\
\text { personagem principal terá que derrotar os monstros resolvendo as operações } \\
\text { básicas), tecnologia (acesso pelo computador), quantidade de jogadores (apenas } \\
\text { um jogador); personagens de jogador (apenas um personagem principal com } \\
\text { duas opções de sprite), cenários (paisagens variadas), desafios (o jogador deverá } \\
\text { fornecer a resposta correta das operações para derrotar os monstros), dentre } \\
\text { outros. }\end{array}$ \\
\hline $\begin{array}{l}\text { Desenvolvimento e } \\
\text { Game Design } \\
\text { Document (GDD) }\end{array}$ & $\begin{array}{l}\text { Desenvolvimento do jogo utilizando a ferramenta Scratch, assim como a } \\
\text { produção do } G D D \text {, documento que apresenta informações detalhadas do jogo. }\end{array}$ \\
\hline Validação & $\begin{array}{l}\text { A etapa consistiu em testes e na avaliação realizada pelo professor da disciplina } \\
\text { e pelos colegas de turma. }\end{array}$ \\
\hline
\end{tabular}

Para o desenvolvimento do game foi usada a plataforma Scratch ${ }^{1}$, ferramenta de fácil manuseio e amplamente utilizada na literatura [Eloy, Lopes e Angelo 2017]. Idealizada pelo Lifelong Kindergarten Group do Massachusetts Institute of Technology (MIT) Media Lab, a plataforma é disponibilizada de forma gratuita na internet e permite a criação de jogos e animações interativas, sendo possível trabalhar com imagens, fotos, música, criar e mudar a aparência dos desenhos.

Todas as imagens utilizadas na construção das cenas e dos sprites foram retiradas dos repositórios gratuitos Game Art $2 D^{2}$, Craftpix.net ${ }^{3}$ e Freepik ${ }^{4}$, além de imagens de autoria própria, criadas utilizando o editor de imagens gratuito GIMP ${ }^{5}$.

\footnotetext{
${ }^{1}$ https://scratch.mit.edu/download/

${ }^{2}$ https://www.gameart2d.com/

${ }^{3}$ https://craftpix.net/

${ }^{4}$ http://br.freepik.com/

${ }^{5}$ https://www.gimp.org/
} 


\section{Apresentação do Software Educacional}

Operação Ninja é um jogo educacional digital que tem como objetivo exercitar e aprimorar os conhecimentos básicos das quatro operações, por meio da resolução de problemas matemáticos.

\subsection{História do jogo}

O jogo conta a história de um mundo (Mundo da Matemática) invadido por monstros que desejam destruir o conhecimento da Matemática. Para vencê-los, o personagem herói precisa acertar os cálculos matemáticos, envolvendo as quatro operações, apresentados por cada monstro.

\subsection{Mecânica do Jogo}

Operação Ninja inicia com a contação da história e as instruções do game. Em seguida, o jogador escolhe seu personagem herói (Takashi - menino ou Shily - menina) representado por um(a) ninja. Depois, este é levado para o Mundo da Matemática para enfrentar um exército de monstros que desejam destruir o conhecimento da Matemática. O exército possui quatro categorias de monstros: zumbis, abóboras, robôs e orcs, cada uma associada as quatro operações matemáticas: soma, subtração, multiplicação e divisão, respectivamente.

O jogo está dividido em quatro fases, cada uma associada a uma operação e categoria de monstro. O objetivo é vencer os chefões e seu exército de monstros presentes nas fases. A única maneira de fazer isso é acertando os cálculos matemáticos apresentados por cada monstro. Os valores dos cálculos são gerados aleatoriamente, entre os números de 1 a 10. Assim, o jogador precisa acertar o cálculo antes de ser atacado pelo inimigo. Se acertar o cálculo, o herói lança uma kunai (adaga) para aniquilar o inimigo, caso contrário, o inimigo ataca, causando danos ao herói.

Ao vencer o exército de cada fase, um chefão aparece exigindo vários cálculos para ser vencido. O game encerra quando o jogador passa por todas as fases, vence todos os monstros e salva o conhecimento da Matemática.

\subsection{Descrição das Telas}

Após o carregamento do jogo, a tela inicial apresenta nome do jogo, alguns personagens e o botão Play para iniciar. Em seguida, o usuário é direcionado para a tela de seleção do personagem herói, que conta a história e apresenta as instruções do jogo (Figura 1).
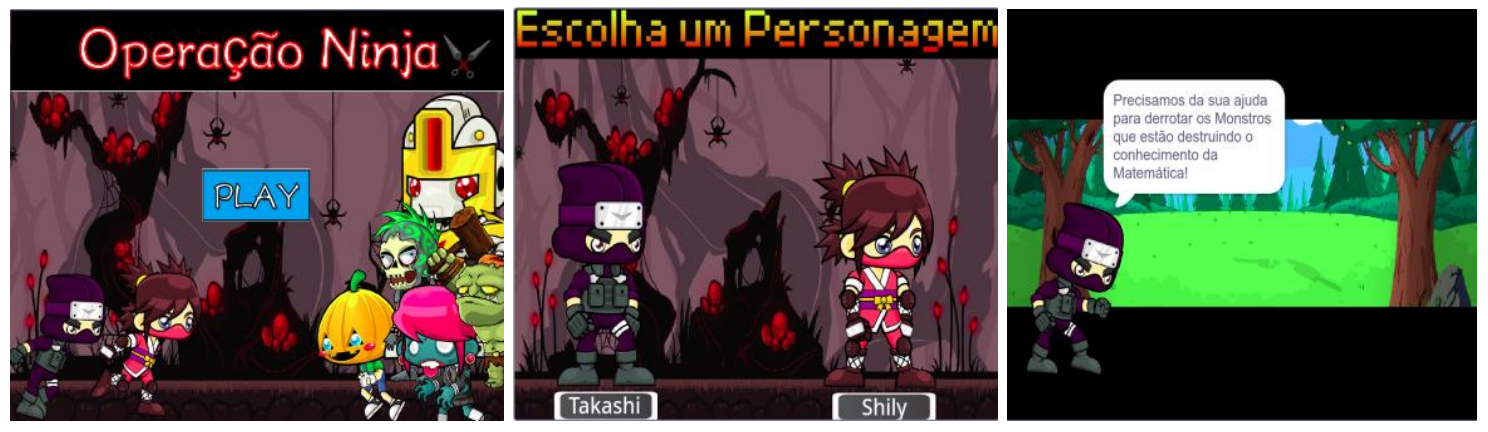

Figura 1. Sequência inicial do jogo 
Uma animação mostra o personagem chegando no Mundo da Matemática. Em cada fase, o herói inicia com três vidas. Seu objetivo é resolver as operações matemáticas associadas a cada monstro (Figura 2).
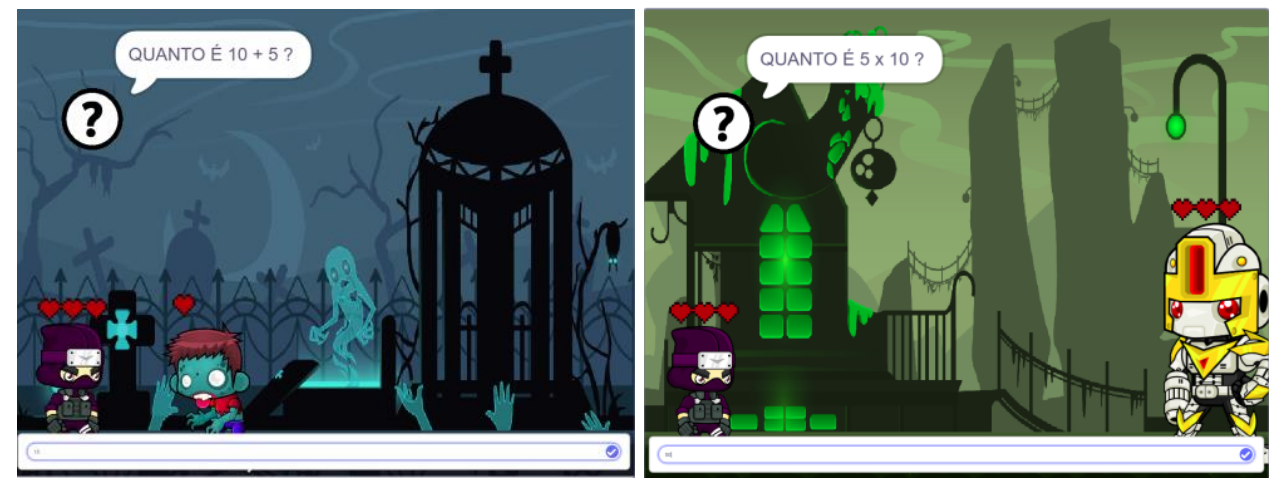

Figura 2. Tela de cálculos matemáticos

A única ação do jogador é responder as perguntas antes de ser atacado pelo inimigo. Se acertar o cálculo, o herói lança uma kunai para derrotá-lo (Figura 3), caso contrário, o inimigo ataca, causando danos ao herói (Figura 4).

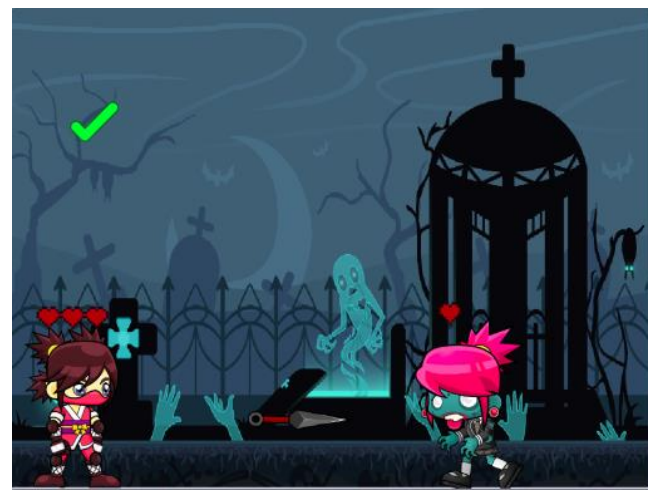

Figura 3. Tela resposta correta

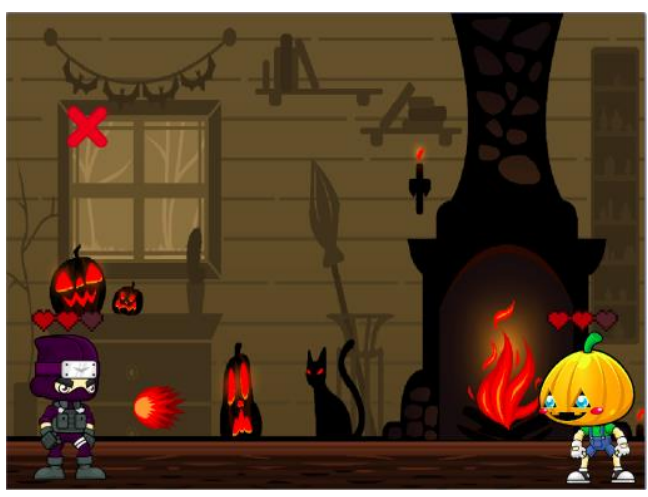

Figura 4. Tela resposta errada

Inicialmente, o usuário precisa vencer o exército da fase. Após derrotar o exército, um chefão aparece exigindo a resolução de vários cálculos para ser vencido. A mudança de fase ocorre após a derrota do chefão de cada fase (Figuras 5). Caso o jogador seja derrotado, o jogo é reiniciado.
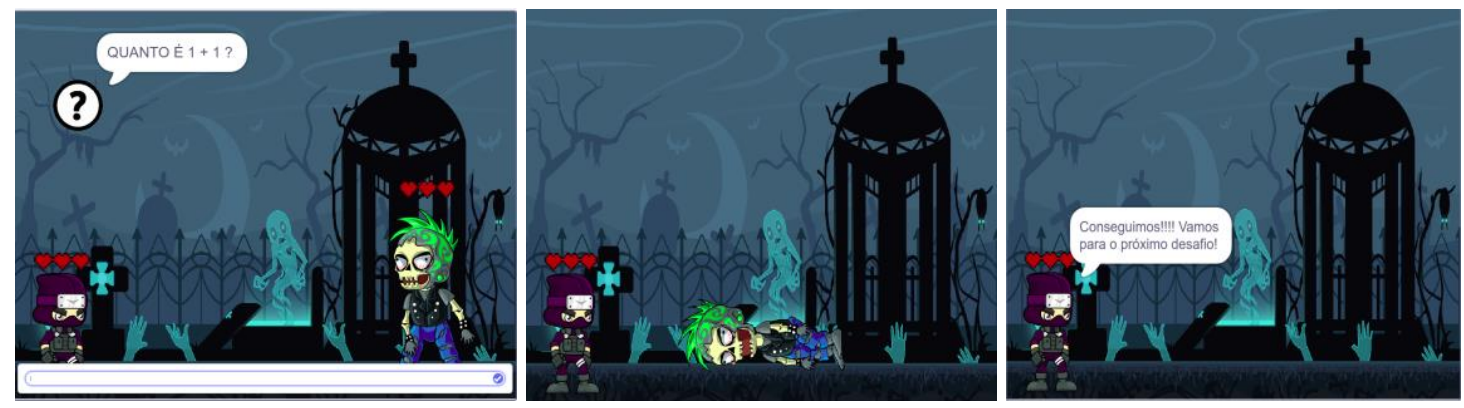

Figura 5. Sequência de luta com vilão e mudança de fase 


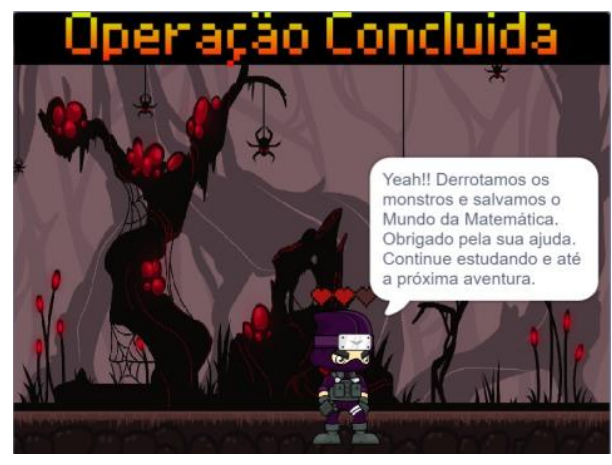

Figura 6. Tela Final

O jogo é finalizado com sucesso, quando o jogador consegue vencer todos os monstros, salvando o Mundo da Matemática (Figura 6).

\section{Considerações Finais}

A utilização do jogo educacional digital Operação Ninja apresenta-se como um auxílio no processo de consolidação das quatro operações básicas de forma lúdica e prazerosa, além de trazer um maior envolvimento e imersão na disciplina de Matemática.

Em uma avaliação inicial pelo professor da disciplina e pelos colegas de turma, Operação Ninja mostrou-se um jogo educacional divertido, estimulante e que traz contribuições positivas para o processo de ensino e aprendizagem das quatro operações básicas da Matemática.

É importante ressaltar que, enquanto protótipo, o jogo ainda não foi aplicado com alunos da série alvo em sala de aula, e possui algumas limitações, como a escolha dos valores dos cálculos de divisão. O jogo ainda está em fase de aperfeiçoamento, como, a inclusão de níveis de dificuldades, tempo para responder as questões, a criação de um super vilão, dentre outros aspectos, no intuito de deixar a aprendizagem ainda mais divertida e desafiadora.

Como trabalhos futuros está prevista a aplicação do software com alunos do $4^{\circ}$ ano do Ensino Fundamental, a fim de avaliar a aplicabilidade do jogo, bem como o feedback dos alunos. Após as melhorias e aperfeiçoamentos das lacunas identificadas no game, será desenvolvida a versão mobile (Android) do jogo educacional, em outra ferramenta, que permita ao estudante baixar o aplicativo para uso no smartphone, ampliando suas formas de acesso.

\section{Referências}

Batista, M. F.; Ramos, R. A.; Brito, L. F de. (2018) "Utilizando o Aplicativo Criptomática para Ensinar Conteúdos Matemáticos do Ensino Médio com Uso da Criptografia”. RENOTE-Revista Novas Tecnologias na Educação, 16(2), p. 362-371.

Brandão, L. et al. (2017) "Ensinando com jogos ou jogando com o ensino: a visão da comunidade brasileira de Informática na Educação sobre jogos no ensino de matemática". In: Brazilian Symposium on Computers in Education (Simpósio Brasileiro de Informática na Educação-SBIE), 29(1), p. 735-744. 
Coelho Neto, J.; Blanco, M. B.; Silva, J. A. (2017) "O Uso de Gamificação e Dificuldades Matemáticas: Possíveis Aproximações". RENOTE-Revista Novas Tecnologias na Educação, 15(1).

Danyluk, O. S. (1988) "Um estudo sobre o significado da alfabetização matemática". Rio Claro (SP): IGCE-UNESP, Dissertação de Mestrado.

Eloy, A. A. S.; Lopes, R. D.; Angelo, I. M. (2017) "Uso do Scratch no Brasil com objetivos educacionais: uma revisão sistemática". RENOTE-Revista Novas Tecnologias na Educação, 15(1).

Gonçalves, A. et al. (2014) "Desenvolvimento de Jogos Educacionais na Área de Matemática em Escola de Ensino Fundamental". In: XIX Congresso Internacional de Informática Educativa. p. 622-627.

Macêdo, P.; Moutinho, M.; Santos, W. (2017) "Jogo Digital como Auxílio no Estudo da Matemática: Um Estudo de Caso com Estudantes do Ensino Fundamental I". In Anais do Workshop de Informática na Escola. 23(1), p. 548-557.

Notare, M. R.; Behar, P. A. (2010) "Comunicação e Aprendizagem Matemática Online: Um Estudo com o Editor Científico ROODA Exata”. Revista Brasileira de Informática na Educação, 18(1), p. 44-52.

Novak, J. (2011) “Game development essentials: an introduction”. Cengage Learning.

Resende, G.; Mesquita, M. G. B. F. (2013) "Principais dificuldades percebidas no processo ensino-aprendizagem de matemática em escolas do município de Divinópolis, MG”. Educação Matemática Pesquisa, São Paulo, 15(1), p. 199-222.

Silva, A. C. B.; Gomes, A. S. (2015) "Conheça e utilize software educativo: avaliação e planejamento para a educação básica”. Recife: Pipa Comunicação.

Souza, F. et al. (2018) "Processo de Desenvolvimento de um Jogo Sério para o Ensino das Quatro Operações Matemáticas". In: Anais dos Workshops do Congresso Brasileiro de Informática na Educação. p. 1147-1156.

Teixeira, R. A. S. (2015) "Jogos digitais como artifício pedagógico na escola atual”. Universidade Federal de Minas Gerais. Dissertação de Mestrado.

Todos pela Educação (2019) “Anuário Brasileiro da Educação Básica”. São Paulo: Moderna. Disponível

em: https://www.todospelaeducacao.org.br/_uploads/_posts/302.pdf. 